Estudos RBEP

\title{
Reforço escolar: gastos e desigualdades sociais
}

\author{
Candido Alberto Gomes \\ Fernando Mariano \\ Adriana de Oliveira \\ Alessandro Barbosa \\ José Hilton B. de Sousa \\ Nidolf Friedrich
}

\section{Resumo}

O reforço e o fracasso escolares coexistem como faces da mesma moeda: um sistema educacional excludente e de qualidade discutível. Assim, o reforço merece ser pesquisado, inclusive por envolver um custo a mais para a sociedade e para os cidadãos. Na perspectiva de mensurar os gastos familiares com essa atividade, foi realizada pesquisa exploratória com alunos do ensino médio de uma escola pública e outra particular do Distrito Federal. Os resultados apontam diferenças significativas nos gastos com reforço escolar, conforme a dependência administrativa da escola, indicando mais um fator de desigualdade social e educacional. Ao contrário do que sugere a literatura, não foi encontrada relação entre o nível de escolaridade da mãe e os gastos em reforço escolar. Assim como em Portugal, também no Brasil o reforço é um meio de promover o sucesso, sobretudo em exames competitivos, suprindo lacunas da escola regular.

Palavras-chave: reforço escolar; professor explicador; economia da educação; custos educacionais; estrutura social; ensino médio. 


\section{Abstract}

Supplementary tutoring: spending and social inequalities

Tutoring and failure coexist as two sides of the same coin: an exclusionary and of dubious quality educational system. Thus, considering that tutoring increases costs to society and, therefore, to their citizens, it should be better investigated. In the perspective of measuring household expenditure on this activity, an exploratory research with high school students in one public and another private school of the Federal District was carried out. The results show significant differences in expenditures on tutoring, depending on the kind of maintenance of the school, indicating another source of social and educational inequality. Unlike the previous literature, no relationship was found between the level of mother's education and expenditure on tutoring. As in Portugal, also in Brazil tutoring is a way to promote success, especially in competitive examinations, filling gaps in regular school.

Keywords: tutoring, economics of education, household expenditure on education, educational costs, social structure, high school.

O fracasso escolar é terreno fértil onde vicejam atividades preventivas e remediativas paralelas à escola. Nada fazer implica altos riscos de reprovação e abandono, cujo custo é maior do que o de evitar que aconteçam. Assim, pais e alunos buscam alternativas nas aulas e atividades de reforço escolar e ainda enriquecem os currículos - ou preenchem lacunas - por meio de cursos paralelos, como os de línguas estrangeiras e os preparatórios para exames mais seletivos. De tais necessidades brota uma espécie de sistema-sombra, não formal ou informal, com um porte e diversificação apreciáveis. Contudo, os custos correspondentes não estão ao alcance de todos, mas daqueles que com eles podem arcar e que, além disso, têm a percepção da sua necessidade, do valor da educação para competir e das implicações negativas do fracasso escolar, bem como da arquitetura de estratégias para o impedir. Com isso, o sistema paralelo atende assimetricamente à sociedade e acrescenta desigualdades ao processo de escolarização, em si desigual. Noutras palavras, este seria em princípio um dos meios pelos quais os herdeiros transmitem o seu capital cultural entre gerações (Bourdieu, Passeron, 1970), em especial quando os pais não têm habilidades ou tempo para fazê-lo e, assim, "terceirizam" parte das suas funções.

Por esses e outros motivos, Costa, Neto-Mendes e Ventura (2008), da Universidade de Aveiro, Portugal, desenvolveram ampla investigação sobre 
esse mercado que se expande em escala transnacional, inclusive por meio de franquias, e que se chama de "explicações". Os autores focalizaram os alunos do $12^{\circ}$ ano, último do ensino secundário, em escolas públicas de uma cidade de porte médio. Discutindo a literatura correspondente, os alunos da disciplina de Economia e Gestão da Educação do Programa de Pós-Graduação em Educação da Universidade Católica de Brasília, no âmbito da Cátedra Unesco de Juventude, Educação e Sociedade, efetuaram uma pesquisa exploratória para fundamentar possíveis estudos ulteriores.

\section{Aproximações sobre o reforço escolar}

Utiliza-se aqui como sinônimo de "explicação" o termo "reforço escolar", também designado no Brasil como tutoria. Para Costa et al. (2007), no que tange ao fazer pedagógico, as explicações são vistas em sua condição de trabalho suplementar às atividades do ensino regular.

No Brasil, tal qual ocorre nos sistemas educacionais mais competitivos, o reforço escolar tem sido, antes, uma enviesada opção de inclusão educacional e de suprimento de deficiências acadêmicas da escola regular, independentemente da esfera administrativa. Essa situação adquire maior visibilidade quando se enfoca o acesso à educação superior pública em países em desenvolvimento, particularmente no Brasil. Onde existem dificuldades escolares e competição relacionadas aos diplomas que dão acesso aos elevadores sociais brotam as necessidades de explicação e reforço. Isso pode ocorrer em países asiáticos, onde a educação é precioso passaporte para a mobilidade social, como revelam pesquisas em Hong-Kong (Bray, 2005) e na República da Coréia (Kim, 2005), em países pós-socialistas ou da África Subsaariana, onde a decadência da escola pública pode ser suprida pelos próprios docentes, e em países tão diferentes entre si como Portugal, Turquia e Bangladesh (Bray, 2008).

No caso de Portugal, o recurso a esses serviços tem maior incidência entre as famílias de escolarização ou formação acadêmica mais elevada. No que tange à situação da atividade perante o Estado, os pesquisadores chamam a atenção para a informalidade predominante nesse setor da economia portuguesa, uma vez que representa parcela significativa do produto interno bruto (PIB) português. A contraprestação fiscal, evidenciada pelo baixo percentual de professores (18\%) emitentes de notas fiscais de seus serviços, denotaria expressiva sonegação.

No caso da Turquia, Tansel e Bircan (2005) dedicaram atenção especial à análise dos custos dos centros de aprendizagem preparatórios para os concorridos exames de acesso à universidade. Ao final, concluíram que os custos desses estabelecimentos não seriam inferiores a 15\% da renda média das famílias que a eles acorrem. Com efeito, a renda familiar e o nível educacional dos pais são determinantes para o desempenho educacional das crianças. Contudo, o impacto da formação da mãe nos gastos com reforço escolar é significativamente maior do que o do nível 
educacional do pai. Outras duas constatações coerentes referem-se ao investimento significativamente maior em reforço escolar pelas famílias residentes em áreas urbanas e pelas mães solteiras.

Nos países do leste europeu que integraram o estudo do Education Supporting Project (ESP), o reforço escolar, sob a forma de aulas ou cursos no final do ensino médio, foi relatado por 56\% dos estudantes da Croácia participantes do levantamento. Na Geórgia, esse percentual foi elevado a 80\%. Na Mongólia, 40\% dos estudantes tinham reforço com os próprios professores da escola regular. No Azerbaijão e na Ucrânia esses números atingiam $25 \%$ e $20 \%$, respectivamente, também envolvendo os professores regulares. A pesquisa indicou possível relação entre reforço escolar e baixo PIB per capita. Para a maioria dos participantes, o reforço escolar era a única forma de obter educação de melhor qualidade.

\section{Reforço escolar: grandezas e misérias}

As apreciações críticas até aqui disponíveis sobre o reforço escolar são divergentes, assinalando vantagens e limitações, se bem que as últimas são mais marcantes que as primeiras. Sob alguns aspectos, não se pode deixar de reconhecer os benefícios da atividade, mas há, igualmente, quem ressalte, como Bray (2008), os efeitos negativos do reforço escolar; para esse autor, os malefícios coletivos da atividade acabam por superar o retorno individual. No que concerne às vantagens, o reforço ajuda os estudantes a desenvolver e ampliar sua competitividade no mercado educacional. Nesse espaço, ele funciona como uma janela de oportunidade para o investimento privado em capital humano, inclusive proporcionando renda a educadores não remunerados. Ainda sob essa ótica, a atividade configura ocupação extraescolar não supervisionada para a juventude. $\mathrm{O}$ crescimento da tutoria privada no novo ambiente dirigido pelo mercado nos antigos países socialistas pode indicar inadequações no sistema educacional (ESP, 2006).

As críticas mais contundentes ao reforço escolar, por sua vez, sugerem um leque de situações negativas derivadas da atividade. Na pesquisa realizada pelo ESP em repúblicas da extinta União Soviética, as consequências incluem a exacerbação das desigualdades sociais, as distorções curriculares e a proposital queda de desempenho dos professores no ensino regular.

No que se refere à desigualdade social, é recorrente o entendimento de que o acesso a oportunidades diferenciadas de serviços educacionais ocasiona situações iníquas. Quando associado à renda familiar, o acesso à educação diferenciada propicia grandes diferenças no retorno educacional, e, consequentemente, desigualdade e injustiça social (Shafiq, 2002).

Não há dúvida de que crianças de famílias com maior renda e recebendo reforço escolar estão aptas a se sair melhor na escola e nas ocupações profissionais que vierem a desempenhar ao longo da vida. Às crianças de menor renda alijadas de tais benefícios resta um grande 
esforço para, pelo menos, dar conta de um desempenho compatível com o de seus colegas de sala. Como nem mesmo esse acompanhamento da turma é possível, elas acabam abandonando a escola mais cedo (Balfanz, McPartland, Shaw, 2002).

Já no que diz respeito ao fato de o reforço informal dar causa à corrupção, parece haver importantes evidências, até mesmo em países como Portugal, onde o reforço escolar aos próprios alunos é vedado por lei, professores prestam o serviço de maneira cruzada, indicando-se mutuamente para o encargo. Com isso, conseguem burlar a norma.

Por fim, o desvirtuamento dos processos de admissão às universidades é revelado no relatório preliminar do ESP (2006). Têm surgido monopólios de serviços de reforço escolar para potenciais candidatos à universidade. O problema é que esses estariam sendo prestados por docentes de universidades, geralmente familiarizados com os conteúdos dos exames. É de se acentuar que a situação se agrava quando esses profissionais exercem algum poder de influência sobre a instituição universitária. Os novos empresários seriam, por assim dizer, sujeitos privilegiados, razão pela qual lograriam proveito pessoal discutível da sua relação com as universidades.

Não é sem motivos, pois, que as recomendações adotadas pelos pesquisadores responsáveis pelo ESP chamam a atenção para a necessidade de se instrumentar a sociedade com vista ao controle do fenômeno. Particularmente, eles reconhecem a urgência de regulamentar a atividade, o que inclui a edição de um código de ética e a previsão de licenciamento ou autorização pelo Estado.

\section{Reforço escolar e custos}

À parte situações excepcionais, como a do programa norte-americano No Child Left Behind, em que o governo é responsável pelo aporte de recursos para o reforço escolar, a oferta da atividade é geralmente remunerada (Anderson, Laguarda, 2005), ainda que tenha como objeto matérias acadêmicas, suplementando o ensino regular. A situação só não é mais crítica porque, em muitos sistemas educacionais, o que inclui o brasileiro e os de países anteriormente integrantes do bloco socialista, a oferta de educação básica é, em princípio, livre de encargos para as famílias, entretanto, a depender do ambiente ou do formato das aulas em que é ofertada, os custos se alteram significativamente.

O reforço escolar se concretiza, principalmente, por meio de aulas individuais ou para pequenos grupos, com um professor, aulas para grandes grupos providas individualmente ou mesmo por meio de uma estrutura empresarial com oportunidades diversificadas (ESP, 2006; Costa, Neto-Mendes, Ventura, 2008). Com efeito, considerando a variabilidade de custos envolvida em cada uma dessas possibilidades, é de se esperar que ele sirva também a públicos distintos, em função da capacidade econômica de cada um. 
Ademais, os custos estão intimamente associados ao retorno educacional do reforço. Não é coincidência que a marca comum dos sistemas educacionais de países onde a prática do reforço escolar é extensiva seja a existência de exames competitivos para ingresso na universidade. A título de exemplo, Coreia do Sul, Japão, Grécia e Turquia, que adotam exame nacional de seleção para as universidades, entrariam nesse rol.

Nos países em desenvolvimento, onde é comum associar-se a falta de qualidade da educação aos baixos recursos por aluno, o reforço escolar tem o desafio de suprir deficiências do sistema educacional, sem, contudo, contribuir para o aprimoramento de sua estrutura. Assim, o número inadequado ou insuficiente de universidades e vagas, a superlotação de salas de aula e o baixo investimento público em educação são frequentemente combatidos por meio da oferta de oportunidades educacionais diferenciadas. Isso não se faz sem custo e geração ou amplificação de desigualdades.

Para alguns estudiosos, assim, o reforço escolar figura como resposta oportuna e adequada do mercado à mediocridade do sistema escolar (Kim, 2005). Entretanto, essa percepção não tem sustentação empírica. A crescente demanda de reforço escolar em muitos países desenvolvidos, como o Canadá, onde tais deficiências são mínimas, é suficiente para negar essa tese. O desempenho, relativamente pífio, dos respectivos estudantes em testes acadêmicos internacionais é dado como razão adicional para a crescente demanda por reforço escolar nos países desenvolvidos.

Essa última situação se aplica, particularmente, ao caso dos Estados Unidos, onde o reforço escolar se originou, a princípio, da necessidade de apoio suplementar a estudantes em vias de fracasso acadêmico em matérias específicas. Hoje, ele constitui um recurso de apoio aos estudantes interessados em melhorar suas notas. Entretanto, essa modalidade de reforço tem sido reconceitualizada (Balfanz, McPartland, Shaw, 2002), e a razão para a mudança do caráter do reforço escolar no país é estratégica: é o posicionamento de liderança da nação no mundo que está posto em xeque. Em números atuais, estima-se que 40\% dos estudantes estadunidenses precisariam de reforço escolar para que o país alcançasse a média mundial de desempenho em matemática em testes como o Programa Internacional de Avaliação de Estudantes (Pisa).

\section{Objetivos e metodologia da pesquisa}

Para a presente pesquisa, de caráter exploratório, deu-se preferência à análise de variáveis supostamente associadas ao investimento das famílias na educação dos filhos. Adicionalmente, procurou-se identificar se a variabilidade dos gastos educacionais da família estaria associada ao nível de escolaridade do lar - notadamente o da mãe, que, em princípio, passa mais tempo com os filhos ou se torna, com maior frequência, chefe do domicílio - e se essa variável, juntamente com a natureza da escola onde o aluno está matriculado, teria alguma relação com as perspectivas de estudo dos pesquisados. 
Desse modo, os objetivos da presente pesquisa incluem: 1) aferir o grau de associação ou correlação entre fatores como a escolaridade da mãe e os gastos com reforço escolar e, ainda, com as expectativas de continuidade de estudos após a conclusão do ensino médio; 2) verificar se existem diferenças significativas no que tange aos gastos em que incorrem as famílias de jovens estudantes do ensino médio, notadamente em razão da natureza da escola frequentada e do nível de escolaridade das mães.

A seleção da amostra foi pautada pela intencionalidade e conveniência. A normalidade da distribuição dos sujeitos e o fato de se tratar de um estudo exploratório mitigam o aparecimento de distorções, uma vez que não se pretende generalizar os resultados, mas tão-somente apreender, com relativa profundidade, os ambientes estudados. Os critérios que nortearam a escolha foram: 1) a representação de uma escola pública e outra particular, visto que, no Brasil, ao contrário de Portugal, é relativamente elevado o percentual de matrículas no setor privado no nível médio (12,0\% em 2006, ou 1.060 mil matrículas, segundo o Instituto Nacional de Estudos e Pesquisas Educacionais Anísio Teixeira - Inep); 2) a inclusão da primeira série, em que incidem os mais altos níveis de abandono e reprovação; 3) a inclusão da terceira série, em que tende a ser maior o esforço competitivo para ingresso na educação superior, em especial a pública e gratuita.

A amostra estudada é composta de 358 estudantes de 14 a 20 anos de idade, predominantemente do sexo feminino, aos quais foi aplicada, no segundo semestre de 2008, com a devida autorização, versão adaptada do questionário da Universidade de Aveiro. Em cada estabelecimento foram sorteadas três turmas, tendo como respondentes todos os alunos presentes.

A primeira escola, confessional, fundada há 45 anos, com atuação em toda a educação básica, tem 1,5 mil matrículas, das quais 360 no ensino médio. Essa escola oferece atividades alternativas, como teatro e dança, cobradas. As atividades de reforço acadêmico, como "aulões", exames simulados e tutoria, já estão incluídas na mensalidade regular, tendendo a subestimar o recurso ao reforço. Mas há cursos preparatórios extraordinários no final do ano, pelos quais a escola cobra aproximadamente $25 \%$ do valor da mensalidade. Como se verá, isso não reduziu drasticamente o apelo ao reforço fora do estabelecimento. Cerca de metade dos estudantes é oriunda de segmentos socioeconômicos ditos privilegiados do Plano Piloto de Brasília (região com renda per capita considerada como das mais elevadas do País), embora não seja um dos estabelecimentos mais caros da área ou uma "escola da moda" entre os adolescentes.

A segunda, um centro escolar de ensino médio público dos mais tradicionais do Distrito Federal, com mais de 40 anos de funcionamento, atendia a cerca de 2,1 mil alunos em duas modalidades de ensino: oferecia as três séries do ensino médio, nos turnos matutino e vespertino e a educação de jovens e adultos (EJA), à noite. A comunidade escolar era composta por alunos de Regiões Administrativas de renda média e baixa do Distrito Federal e até de municípios do seu entorno. As unidades públicas tendem a receber alunos de menor renda, porém, se um desses 
estabelecimentos integrasse a pesquisa, seriam provavelmente raros os casos de pagamento de reforço.

Cabe registrar que, na edição de 2007 do Exame Nacional do Ensino Médio (Enem), de acordo com dados do Inep, ambas as escolas registraram desempenhos médios bastante próximos: enquanto a escola privada, que participou do exame com 18 alunos, obteve escore médio de 57,01, os 202 alunos da escola pública alcançaram a nota média de 59,39 pontos. A participação de discentes nessa avaliação oficial é voluntária, valendo para o acesso a determinadas instituições de educação superior. Ademais, é compulsória para os candidatos de baixa renda a um auxílio financeiro federal, para estudo em estabelecimento particular de educação superior. A população do Enem não constitui, assim, uma amostra representativa do alunado. Os dados foram processados por meio do programa Statistical Package for the Social Sciences (SPSS).

\section{Quantos buscam o reforço?}

Conforme se extrai da Tabela 1, a distribuição dos estudantes pesquisados por idade, sexo e natureza da escola frequentada evidencia, por um lado, o predomínio de pessoas do sexo feminino, com percentual em torno de 60,0\%, em ambos os estabelecimentos pesquisados. Essa constatação guarda consonância com a realidade educacional do País, onde o acesso da mulher à educação já ultrapassou o do homem há algumas décadas. No que tange à idade considerada adequada para a frequência a esse nível de ensino, é certo que ambas as escolas apresentam problemas, mas nada que se compare à realidade educacional do País quanto à distorção idade-série (44,5\% no ensino médio em 2006, segundo o Inep). A presença de número não desprezível de estudantes com 18 anos e mais nas duas escolas patenteia essa distorção.

Tabela 1 - Distribuição de frequência dos respondentes por idade, segundo a dependência administrativa e o sexo

\begin{tabular}{|c|c|c|c|c|c|c|}
\hline \multirow{4}{*}{ Idade } & \multicolumn{6}{|c|}{ Dependência administrativa } \\
\hline & \multicolumn{3}{|c|}{ Escola pública } & \multicolumn{3}{|c|}{ Escola privada } \\
\hline & \multicolumn{2}{|c|}{ Sexo } & \multirow{2}{*}{ Total } & \multicolumn{2}{|c|}{ Sexo } & \multirow{2}{*}{ Total } \\
\hline & Feminino & Masculino & & Feminino & Masculino & \\
\hline 14 & 1 & 1 & 2 & 2 & 0 & 2 \\
\hline 15 & 28 & 13 & 41 & 36 & 16 & 52 \\
\hline 16 & 24 & 18 & 42 & 10 & 18 & 28 \\
\hline 17 & 37 & 24 & 61 & 41 & 25 & 66 \\
\hline 18 & 7 & 8 & 15 & 14 & 14 & 28 \\
\hline 19 & 4 & 1 & 5 & 0 & 2 & 2 \\
\hline 20 & 1 & 0 & 1 & 0 & 0 & 0 \\
\hline Total & 102 & 65 & 167 & 103 & 75 & 178 \\
\hline Percentual & $61 \%$ & $39 \%$ & $100 \%$ & $58 \%$ & $42 \%$ & $100 \%$ \\
\hline
\end{tabular}

Fonte: Pesquisa de campo.

De acordo com a Tabela 2, que registra a busca de reforço escolar desagregada por dependência administrativa, o percentual de alunos 
da escola pública que demanda tais serviços em termos relativos (22\%) corresponde a menos da metade do percentual de seus colegas da escola privada (52\%), a despeito de esta última oferecer atividades similares já incluídas na mensalidade. Neste caso específico foram consideradas as aulas de reforço, excluindo outros cursos. Partindo do pressuposto de que à escola pública acorrem estudantes de menor poder aquisitivo, o resultado se mostra coerente com as constatações sobre o tema, que costumam associar a utilização do serviço de reforço escolar à capacidade econômica da família. Ainda que se relativize esse dado, já que a unidade escolar pública tinha condições diferenciadas da maioria das escolas do mesmo segmento, a constatação se mostra adequada.

Tabela 2 - Alunos que recorrem a aulas de reforço por dependência administrativa da escola regular frequentada

\begin{tabular}{|c|c|c|c|c|c|c|}
\hline \multirow{3}{*}{$\begin{array}{c}\text { Dependência } \\
\text { administrativa }\end{array}$} & \multicolumn{4}{|c|}{ Aula de reforço } & \multirow{2}{*}{\multicolumn{2}{|c|}{ Total }} \\
\hline & \multicolumn{2}{|c|}{ Não } & \multicolumn{2}{|c|}{ Sim } & & \\
\hline & Número & $\%$ & Número & $\%$ & Número & $\%$ \\
\hline Pública & 135 & 78,0 & 38 & 22,0 & 173 & 100,0 \\
\hline Privada & 88 & 48,1 & 95 & 51,9 & 183 & 100,0 \\
\hline Total & 223 & 62,6 & 133 & 37,4 & 356 & 100,0 \\
\hline
\end{tabular}

Fonte: Pesquisa de campo.

Ao se estratificar a distribuição anterior, com o acréscimo de informação por série (Tabela 3), verifica-se pequena variação entre a primeira e a terceira séries e em sentido inverso, nas duas dependências administrativas. Uma possível explicação para esse movimento oposto consiste na forma e nos tipos de serviços demandados pelas diferentes famílias. É provável que as famílias de menor renda, que têm seus filhos na escola pública, optem por garantir o reforço acadêmico na terceira série, à véspera dos processos seletivos de acesso à universidade. Já as famílias dos estudantes da escola privada proporcionariam a seus filhos um leque de atividades de complementação da formação integral, que tenderia a ser reduzido ao longo do curso.

Tabela 3 - Frequência a aulas de reforço por dependência administrativa da escola e série

\begin{tabular}{|c|c|c|c|c|c|c|c|}
\hline \multirow{3}{*}{$\begin{array}{c}\text { Dependência } \\
\text { administrativa }\end{array}$} & \multirow{3}{*}{ Série } & \multicolumn{4}{|c|}{ Aula de reforço } & \multirow{2}{*}{\multicolumn{2}{|c|}{ Total }} \\
\hline & & \multicolumn{2}{|c|}{ Não } & \multicolumn{2}{|c|}{ Sim } & & \\
\hline & & Número & $\%$ & Número & $\%$ & Número & $\%$ \\
\hline \multirow{3}{*}{ Pública } & $1^{\mathrm{a}}$ & 74 & 81,3 & 17 & 18,7 & 91 & 100,0 \\
\hline & $3^{a}$ & 61 & 74,4 & 21 & 25,6 & 82 & 100,0 \\
\hline & Total & 135 & 78,0 & 38 & 22,0 & 173 & 100,0 \\
\hline \multirow{3}{*}{ Privada } & $1^{\circ}$ ano & 37 & 44,6 & 46 & 55,4 & 83 & 100,0 \\
\hline & $3^{\circ}$ ano & 51 & 51,0 & 49 & 49,0 & 100 & 100,0 \\
\hline & Total & 88 & 48,1 & 95 & 51,9 & 183 & 100,0 \\
\hline \multirow{3}{*}{ Total } & $1^{\circ}$ ano & 111 & 63,8 & 63 & 36,2 & 174 & 100,0 \\
\hline & $3^{\circ}$ ano & 112 & 61,5 & 70 & 38,5 & 182 & 100,0 \\
\hline & Total & 223 & 62,6 & 133 & 37,4 & 356 & 100,0 \\
\hline
\end{tabular}

Fonte: Pesquisa de campo. 


\section{Reforço escolar e gastos familiares com educação}

Para fins de balizamento, menciona-se como parâmetro de gasto desse nível de ensino, no setor público de todo o Brasil, o valor unitário anual, que, em 2006, foi de $\mathrm{R} \$$ 1.417,00 (Brasil.Inep, 2000-2008). Por sua vez, o valor anual estimado por aluno para o ensino médio público urbano no Distrito Federal, em 2008, foi de R\$ 2.254,38, nos termos do Fundo de Manutenção e Desenvolvimento da Educação Básica e de Valorização dos Profissionais da Educação (Fundeb). Ressalve-se, entretanto, que essas opções podem ser justificadas, mas não tomadas por absolutas, em face da indisponibilidade de indicador mais consistente ou apropriado. De todo modo, o indicador de gasto por aluno tem a vantagem de ser público e oficial, servindo, assim, a esse tipo de comparação. Para o setor privado, tomou-se como referência o valor da anuidade cobrada pela escola estudada, que, no exercício de 2008, foi de R\$ 6.424,20. ${ }^{1}$

A par desses dados e à vista da Tabela 4, os resultados da pesquisa também se comportam dentro do quadro esperado. Considerando, porém, que a média do gasto mensal dos estudantes de escola pública em aulas de reforço ( $\mathrm{R} \$ 188,21)$ seja igual a $56,5 \%$ do de seus colegas da escola privada ( $\mathrm{R} \$ 333,27)$, os dois grupos foram homogeneizados para fins de comparação das respectivas médias, obtendo-se valores muito semelhantes.

No que afeta a incidência desse gasto sobre o total da escola regular, observação semelhante pode ser feita. Levando em conta que, observadas eventuais distorções de metodologia de cálculo, o valor por aluno do ensino médio público urbano do Distrito Federal tenha sido previsto em $\mathrm{R} \$ 2.254,38$ para 2008, o gasto anual com reforço escolar dos alunos da escola pública pesquisados chegou a $\mathrm{R} \$ 2.258,52$, considerando-se os 12 meses do ano, ou 100,2\% do valor médio per capita projetado pelo poder público para essa etapa da educação básica (Brasil. FNDE, 2009).

Em relação ao pagamento da escola regular, os pais de alunos da rede privada gastaram anualmente, por filho, o equivalente a $\mathrm{R} \$$ $6.424,20$, o que representa desembolso equivalente a $285 \%$ do valor per capita previsto pelo poder público no ensino médio. Como o gasto anual com reforço escolar é de $\mathrm{R} \$ 3.999,24$, ou 62,3\% do valor da anuidade, o total de gastos por filho (escola regular mais educação extraescolar) alcança $\mathrm{R} \$ 10.423,44$. Além disso, como contribuintes, os pais pagam pela educação pública pelo menos a cifra mencionada do Fundeb, R\$ 2.254,38, o que eleva a importância ao total de R\$12.677,82 anuais. O abatimento de despesas com "instrução" do Imposto de Renda de Pessoa Física (singular) em 2008 foi limitado a R\$ 2.480,66, só podendo incluir pagamentos da educação regular, excluídos os gastos com reforço ou qualquer forma de educação extraescolar (Brasil. Ministério da Fazenda, 2009). Subtraindo essa importância da anuidade da escola particular, cujo valor é relativamente modesto para o Distrito Federal, chega-se a R\$10.197,16 por dependente. Por sua vez, o hipotético responsável por

\footnotetext{
1 Salvo indicação em contrário, todos os valores são nominais. A conversão de moedas se fez com base nas cotações do Banco Central Europeu. Disponível em: <http://sdw.ecb.europa. eu/browseTable.do?DATASET $=$ O\&node $=2018794 \&$ FREQ $=A \&$ SERIES_KEY $=120$. EXR.A.BRL. EUR.SPOOO.A>. Acesso em: 10 jan. 2009.
} 
filho único matriculado no ensino médio público urbano despenderia o aporte de $\mathrm{R} \$ 2.254,38$ mais $\mathrm{R}$ \$ 2.258,52 em educação extraescolar, isto é, um total de $\mathrm{R} \$ 4.512,90$. Tratando-se de educação extraescolar, o contribuinte não poderia deduzir essas despesas do Imposto de Renda ou, se a sua faixa fosse de menor contribuição, teria o desconto padrão de 20\% sobre os ganhos. Essas estimativas de caráter apenas ilustrativo mostram que o sistema tributário exerce a função de Robin Hood. Porém, qualquer diferencial que um responsável precise acrescentar ao ensino público tem elevado custo relativo, com o comprometimento proporcionalmente maior do orçamento das famílias usuárias quanto menor o rendimento. Em outras palavras, a baixa qualidade e o fracasso escolar têm efeitos tão mais perversos quanto menor é a renda familiar.

Tabela 4 - Gasto mensal médio com aulas de reforço, segundo a dependência administrativa da escola (em $\mathbf{R} \$$ correntes)

\begin{tabular}{|c|c|c|c|c|}
\hline \multirow{2}{*}{ Item } & \multirow{2}{*}{$\begin{array}{l}\text { Respondentes (N) } \\
\text { e Valor (em R\$) }\end{array}$} & \multicolumn{2}{|c|}{ Dependência administrativa } & \multirow{2}{*}{ Total } \\
\hline & & Pública & Privada & \\
\hline \multirow{2}{*}{ Reforço total } & $\mathrm{N}$ & 48 & 110 & 158 \\
\hline & Valor & 162,68 & 313,18 & 267,46 \\
\hline \multirow{2}{*}{$\begin{array}{l}\text { Material } \\
\text { didático }\end{array}$} & $\mathrm{N}$ & 46 & 77 & 123 \\
\hline & Valor & 10,09 & 10,03 & 10,05 \\
\hline \multirow{2}{*}{ Transporte } & $\mathrm{N}$ & 57 & 68 & 125 \\
\hline & Valor & 15,44 & 10,06 & 12,51 \\
\hline \multicolumn{2}{|c|}{ Total (R\$) } & 188,21 & 333,27 & 290,02 \\
\hline
\end{tabular}

Fonte: pesquisa de campo.

A realização do Teste t (Tabela 5), com vista a comparar as médias de diversos tipos de gastos dos grupos, registra diferença significativa na despesa com reforço escolar em que incorrem as famílias dos dois segmentos. A probabilidade de divergência atribuível ao acaso é inferior a uma ocorrência em mil casos. Por isso, pode-se assegurar que as diferenças detectadas em relação a esse ponto são estatisticamente significantes. A tabela de médias ajuda a melhor visualizá-las.

Tabela 5 - Teste t para comparação de médias de diversos tipos de gastos

\begin{tabular}{|l|c|c|c|} 
& \multicolumn{3}{c}{ Teste } \\
\cline { 2 - 5 } \multicolumn{1}{c}{ Variáveis } & $\mathbf{t}$ & $\mathbf{g l}^{\left({ }^{(1)}\right.}$ & $\mathbf{P}<$ \\
\hline Gasto com reforço escolar & $-3,93$ & 153,66 & 0,0001 \\
\hline Gasto com material didático das aulas regulares & $-18,98$ & 196,61 & 0,0001 \\
\hline Gasto com material didático do reforço & $-0,31$ & 100,74 & 0,976 \\
\hline Gasto com transporte para as aulas regulares & $-1,27$ & 156,96 & 0,204 \\
\hline Gasto com transporte para aulas de reforço & $-1,96$ & 123 & 0,053 \\
\hline
\end{tabular}

Fonte: Pesquisa de campo.

Nota: ${ }^{(1)}$ graus de liberdade. 
Ainda em relação aos gastos, buscou-se comparar aqueles efetuados pelos estudantes em função do nível de escolaridade de suas mães. Para tanto, os estudantes foram agrupados em dois conjuntos: um constituído por filhos de mães sem escolaridade, indo até a educação básica completa, e outro que congrega os filhos de mães com passagem pela educação superior, até o nível de doutorado. A investigação desse aspecto assume particular relevância, por ser considerado, pela literatura, crucial e determinante dos gastos educacionais da família, particularmente com o reforço escolar, devido ao seu impacto superior ao que decorre da escolaridade do pai.

Os resultados da estatística básica constantes da Tabela 6 apontam diferença significativa nos gastos com reforço escolar e com material didático da escola regular. Entretanto, a ocorrência é inusitada, uma vez favorável às mães com menor escolaridade, o que destoa das pesquisas sobre o tema, que, a rigor, apontam situação diametralmente oposta, como em Portugal. Observe-se que os valores aqui se referem às aulas de reforço e ao total dos cursos extraescolares.

Tabela 6 - Gasto mensal das aulas de reforço e do total dos cursos extraescolares, segundo o nível de escolaridade da mãe (estatística básica)

\begin{tabular}{|l|c|c|c|c|}
\hline \multirow{2}{*}{\multicolumn{1}{|c}{ Variável }} & \multicolumn{4}{c|}{ Nível de escolaridade da mãe } \\
\cline { 2 - 5 } & Até educação básica & \multicolumn{2}{c|}{ Educação superior } \\
\cline { 2 - 5 } & Média & DP & Média & DP \\
\hline Gasto com reforço escolar & 317,66 & 375,49 & 201,02 & 160,76 \\
\hline $\begin{array}{l}\text { Gasto com material didático } \\
\text { do reforço }\end{array}$ & 118,78 & 141,57 & 122,70 & 120,59 \\
\hline Transporte & 16,07 & 14,59 & 9,95 & 8,84 \\
\hline
\end{tabular}

Fonte: Pesquisa de campo.

Se as médias e desvios-padrões oferecem apenas indícios de que pode haver diferenças entre os valores referentes aos gastos associados ao nível de escolaridade das mães, a decisão a respeito do grau de significância da diferença detectada não pode prescindir da realização do Teste t. Para o presente caso, os dados são os constantes da Tabela 7, que de algum modo ratificam as diferenças aferidas por meio das médias. Com efeito, parece afastada a possibilidade de que a diferença em foco possa ser atribuída ao acaso.

Tabela 7 - Teste t para comparação de médias de diversos tipos de gastos

\begin{tabular}{|c|c|c|c|}
\hline \multirow{2}{*}{ Variáveis/gastos } & \multicolumn{3}{|c|}{ Teste } \\
\hline & $\mathbf{t}$ & $\mathbf{g l}^{(1)}$ & $\mathbf{P}<$ \\
\hline Reforço escolar & 2,78 & 110,83 & 0,005 \\
\hline Material didático - aulas regulares & 7,18 & 340 & 0,0001 \\
\hline Material didático - reforço & $-0,20$ & 179 & 0,845 \\
\hline Transporte - aulas regulares & $-1,54$ & 257 & 0,125 \\
\hline Transporte - aulas de reforço & $-1,68$ & 123 & 0,095 \\
\hline
\end{tabular}

Fonte: Pesquisa de campo.

Nota: ${ }^{(1)}$ graus de liberdade. 
De qualquer modo, o gasto considerado nesse caso como função do nível de escolaridade da mãe, antes agregado em dois grandes grupos, passou a dez categorias, sendo que o da educação básica incluiu maior número de níveis. Seriam necessários outros testes para certificar-se acerca da contribuição do agrupamento, nos moldes em que foi feito, para a distorção.

\section{Reforço escolar e gasto total}

De acordo com a Tabela 8, quase metade (47\%) dos alunos da escola pública frequentava pelo menos um curso extraescolar. Na escola privada, a participação era maior, alcançando 62\%. Não há evidência de a escolaridade da mãe ser uma variável determinante para o envio dos filhos a cursos extraescolares, de modo a confirmar a hipótese segundo a qual, estritamente sob este aspecto, o reforço constituiria um dos meios para transmitir intergeracionalmente o capital cultural.

Tabela 8 - Alunos em cursos extraescolares, segundo a dependência administrativa da escola regular frequentada e a escolaridade da mãe

\begin{tabular}{|c|c|c|c|c|c|c|c|}
\hline \multirow{3}{*}{$\begin{array}{c}\text { Dependência } \\
\text { administrativa }\end{array}$} & \multirow{3}{*}{$\begin{array}{c}\text { Escolaridade da } \\
\text { mãe }\end{array}$} & \multicolumn{4}{|c|}{ Cursos fora da escola } & \multirow{2}{*}{\multicolumn{2}{|c|}{ Total }} \\
\hline & & \multicolumn{2}{|c|}{ Nenhum } & \multicolumn{2}{|c|}{$\begin{array}{c}\text { Um ou } \\
\text { mais cursos }\end{array}$} & & \\
\hline & & $\mathbf{N}^{\mathbf{O}}$ & $\%$ & $\mathbf{N}^{\mathbf{O}}$ & $\%$ & $\mathbf{N}^{\mathrm{o}}$ & $\%$ \\
\hline \multirow{3}{*}{ Pública } & $\begin{array}{l}\text { Até educação } \\
\text { básica }\end{array}$ & 78 & 54,2 & 66 & 45,8 & 144 & 100,0 \\
\hline & Educação superior & 14 & 46,7 & 16 & 53,3 & 30 & 100,0 \\
\hline & Total & 92 & 52,9 & 82 & 47,1 & 174 & 100,0 \\
\hline \multirow{3}{*}{ Privada } & $\begin{array}{l}\text { Até educação } \\
\text { básica }\end{array}$ & 21 & 42,9 & 28 & 57,1 & 49 & 100,0 \\
\hline & Educação superior & 50 & 37,0 & 85 & 63,0 & 135 & 100,0 \\
\hline & Total & 71 & 38,6 & 113 & 61,4 & 184 & 100,0 \\
\hline \multirow{3}{*}{ Total } & $\begin{array}{l}\text { Até educação } \\
\text { básica }\end{array}$ & 99 & 51,3 & 94 & 48,7 & 193 & 100,0 \\
\hline & Educação superior & 64 & 38,8 & 101 & 61,2 & 165 & 100,0 \\
\hline & Total & 163 & 45,5 & 195 & 54,5 & 358 & 100,0 \\
\hline
\end{tabular}

Fonte: Pesquisa de campo.

Com o intuito de melhor aferir essa questão, o indicador do nível de escolaridade da mãe foi transformado em anos de escolaridade. Assim, ao se buscar a associação (Tabela 9) entre o gasto em reforço escolar e o gasto educacional com os anos de escolaridade da mãe, obteve-se uma correlação positiva, da ordem de 19\% ( $r=0,194$; $p<0,004)$. Essa correlação, que dificilmente poderia ser atribuída ao acaso, não é desprezível. Entretanto, ela não é considerada estatisticamente significante. Com 
efeito, corrobora-se a percepção de que o nível de escolaridade da mãe, pelo menos nesse caso, não se confirmou como variável determinante para o consumo de serviços de reforço escolar, ao contrário de Portugal, em que foi constatada relação entre essas duas variáveis (Costa, NetoMendes, Ventura, 2008).

Tabela 9 - Associação entre variáveis de gasto

\begin{tabular}{|c|c|c|c|c|c|c|}
\hline \multirow{2}{*}{ Variáveis } & \multirow{2}{*}{\multicolumn{2}{|c|}{$\begin{array}{c}\text { Gasto } \\
\text { com } \\
\text { reforço }\end{array}$}} & \multicolumn{2}{|c|}{ Material didático } & \multirow{2}{*}{$\begin{array}{c}\text { Gasto com } \\
\text { transporte } \\
\text { regular }\end{array}$} & \multirow{2}{*}{$\begin{array}{c}\text { Escolaridade } \\
\text { da mãe }\end{array}$} \\
\hline & & & Regular & Reforço & & \\
\hline \multirow{2}{*}{ Idade } & r & 0,081 & $-0,083$ & $0,200^{* *}$ & $-0,023$ & 0,051 \\
\hline & $\mathrm{p}$ & 0,224 & 0,129 & 0,007 & 0,716 & 0,243 \\
\hline \multirow{2}{*}{ Gasto com reforço } & r & & $-0,158^{* *}$ & 0,084 & $0,186^{*}$ & $0,194^{* *}$ \\
\hline & $\mathrm{p}$ & & 0,029 & 0,330 & 0,026 & 0,004 \\
\hline \multirow{2}{*}{$\begin{array}{l}\text { Gasto com } \\
\text { material regular }\end{array}$} & r & & & 0,14 & $0,182^{* *}$ & $0,363^{* *}$ \\
\hline & $\mathrm{p}$ & & & 0,86 & 0,008 & 0,0001 \\
\hline \multirow{2}{*}{$\begin{array}{l}\text { Gasto com } \\
\text { material do reforço }\end{array}$} & r & & & & 0,178 & 0,023 \\
\hline & $\mathrm{p}$ & & & & 0,062 & 0,762 \\
\hline \multirow{2}{*}{$\begin{array}{l}\text { Gasto com } \\
\text { transporte regular }\end{array}$} & r & & & & & 0,110 \\
\hline & $\mathrm{p}$ & & & & & 0,076 \\
\hline
\end{tabular}

Fonte: Pesquisa de campo.

Nota: ${ }^{* *} \mathrm{p}<0,01 ;{ }^{*} \mathrm{p}<0,05$.

O percentual de mães cujos filhos tinham reforço escolar varia em função da dependência administrativa da escola e do tipo de curso preferido. Exceção deve ser feita à frequência a cursos de inglês e matemática, assemelhados entre os quatro agrupamentos. Os alunos da escola pública cujas mães têm menor grau de escolaridade tendiam a valorizar mais as aulas de informática. Pode haver muitos motivos para tanto, entre eles o diferencial de acesso a computadores. No mesmo segmento, observou-se número expressivo de estudantes cursando uma língua estrangeira que não o inglês; é provável que isso decorra da percepção do espanhol como idioma mais parecido com o português e, assim, de mais fácil aprendizado.

Na escola pública detectou-se opção expressiva, bastante aproximada em termos percentuais, pelas aulas de esportes e preparatórias para o vestibular. Ao contrário, entre os alunos da escola privada verificou-se acentuado predomínio dos cursos preparatórios para exames de acesso ao curso superior. Seguiu-se a essa opção a preocupação das famílias com a realização de algum esporte, área em que foi expressiva a participação dos estudantes cujas mães frequentaram o ensino superior. 
Tabela 10 - Percentual dos cursos extraescolares frequentados, segundo a escolaridade da mãe e a dependência administrativa da escola

\begin{tabular}{|c|c|c|c|c|c|c|c|}
\hline \multirow{3}{*}{$\begin{array}{c}\text { Dependência } \\
\text { administrativa }\end{array}$} & \multirow{3}{*}{$\begin{array}{l}\text { Tipos de cursos } \\
\text { extraescolares }\end{array}$} & \multicolumn{4}{|c|}{ Escolaridade da mãe } & & \\
\hline & & \multicolumn{2}{|c|}{$\begin{array}{c}\text { Até educação } \\
\text { básica }\end{array}$} & \multicolumn{2}{|c|}{$\begin{array}{c}\text { Educação } \\
\text { superior }\end{array}$} & \multicolumn{2}{|c|}{ Total } \\
\hline & & $\mathbf{N}^{\mathbf{o}}$ & $\%$ & $\mathbf{N}^{\mathbf{o}}$ & $\%$ & $\mathrm{~N}^{\mathrm{o}}$ & $\%$ \\
\hline \multirow{8}{*}{ Pública } & Português & 2 & 2,6 & 1 & 5,6 & 3 & 3,1 \\
\hline & Inglês & 30 & 38,5 & 9 & 50,0 & 39 & 40,6 \\
\hline & $\begin{array}{l}\text { Outra língua } \\
\text { estrangeira }\end{array}$ & 9 & 11,5 & 1 & 5,6 & 10 & 10,4 \\
\hline & Matemática & 3 & 3,8 & 1 & 5,6 & 4 & 4,2 \\
\hline & Computação & 15 & 19,2 & 2 & 11,1 & 17 & 17,7 \\
\hline & Esportes & 10 & 12,8 & 2 & 11,1 & 12 & 12,5 \\
\hline & Vestibular & 9 & 11,5 & 2 & 11,1 & 11 & 11,5 \\
\hline & Total & 78 & 100,0 & 18 & 100,0 & 96 & 100,0 \\
\hline \multirow{8}{*}{ Privada } & Português & 2 & 5,1 & 1 & 0,7 & 3 & 1,7 \\
\hline & Inglês & 14 & 35,9 & 44 & 32,4 & 58 & 33,1 \\
\hline & $\begin{array}{l}\text { Outra língua } \\
\text { estrangeira }\end{array}$ & 0 & 0,0 & 10 & 7,4 & 10 & 5,7 \\
\hline & Matemática & 2 & 5,1 & 7 & 5,1 & 9 & 5,1 \\
\hline & Computação & 1 & 2,6 & 4 & 2,9 & 5 & 2,9 \\
\hline & Esportes & 7 & 17,9 & 37 & 27,2 & 44 & 25,1 \\
\hline & Vestibular & 13 & 33,3 & 33 & 24,3 & 46 & 26,3 \\
\hline & Total & 39 & 100,0 & 136 & 100,0 & 175 & 100,0 \\
\hline \multirow{8}{*}{ Total } & Português & 4 & 3,4 & 2 & 1,3 & 6 & 2,2 \\
\hline & Inglês & 44 & 37,6 & 53 & 34,4 & 97 & 35,8 \\
\hline & $\begin{array}{l}\text { Outra língua } \\
\text { estrangeira }\end{array}$ & 9 & 7,7 & 11 & 7,1 & 20 & 7,4 \\
\hline & Matemática & 5 & 4,3 & 8 & 5,2 & 13 & 4,8 \\
\hline & Computação & 16 & 13,7 & 6 & 3,9 & 22 & 8,1 \\
\hline & Esportes & 17 & 14,5 & 39 & 25,3 & 56 & 20,7 \\
\hline & Vestibular & 22 & 18,8 & 35 & 22,7 & 57 & 21,0 \\
\hline & Total & 117 & 100,0 & 154 & 100,0 & 271 & 100,0 \\
\hline
\end{tabular}

Fonte: Pesquisa de campo.

\section{Cotejo entre Brasil e Portugal}

As duas pesquisas, até certo ponto, parecem realizadas em diferentes galáxias. Em 2007, o PIB por habitante de Portugal e Brasil era, respectivamente, de 15,3 mil e 6,9 mil (Instituto Nacional de Estatísticas e Banco Mundial). Os coeficientes de Gini no mesmo ano eram, respectivamente, de 0,385 e 0,570 (Programa das Nações Unidas para o Desenvolvimento), ou seja, o Brasil tinha perto do dobro da concentração de renda de Portugal (maior 
concentração quanto mais próximo de 1,0). A população da Cidade Aquarela (nome suposto, por motivo de ética), onde foi realizada a pesquisa somente em escolas públicas, aproximava-se dos 100 mil habitantes, enquanto o Distrito Federal ultrapassava os dois milhões de residentes. É bem verdade que o PIB per capita do Distrito Federal alcançava, em 2006, nada menos que 13,8 mil, porém com o coeficiente de Gini superior ao do País em 2007, isto é, 0,614 (Ipeadata), o que indica distribuição mais desigual da renda.

Ainda assim, vale destacar que o percentual de discentes que em Portugal recorria às explicações no $12^{\circ}$ ano variou de $54,1 \%$ a $59,4 \%$ nos três anos acadêmicos observados (2004-5 a 2006-7). No Brasil, com as notórias diferenças entre escolas públicas e particulares, os valores se aproximaram, caso se considere o total de cursos e aulas extraescolares: $47,1 \%$ para a escola pública e $61,4 \%$ para a escola privada (Tabela 8).

Quanto às disciplinas mais procuradas, a Matemática, a Química e a Geometria Descritiva lideraram em Portugal. No Brasil predominou o Inglês, seguido pelo preparo em geral para o acesso à educação superior. Na escola pública destacou-se a Informática, possível fruto da consciência do divisor digital e de sua importância para a empregabilidade. Os esportes também alcançaram percentuais relativamente elevados. Os números sugerem que nos dois países o ensino das disciplinas e práticas em tela carece de urgente melhoria.

Os valores médios dos gastos mensais são díspares: em Portugal, as médias variaram de 98,87 a 107,18; no Brasil, os gastos médios mensais somente com reforço escolar foram de 1.053 e 2.817 anuais, respectivamente, nas escolas pública e particular. Entretanto, esses valores médios, considerando o gasto total com o reforço e cursos extraescolares, variaram de 118,81 mensais, para as mães com até educação básica, a 75,18 mensais, para as mães com educação superior, verificando-se uma média geral de 100,03. Considerando as diferenças do PIB per capita entre os dois países, o esforço financeiro no Brasil é expressivo, ainda mais se incluídos os gastos com transporte e materiais.

Numa comparação geral e apenas ilustrativa, a despesa média anual por aluno no ensino secundário de Portugal foi de 5.323 em 2003, segundo a Organização para Cooperação e Desenvolvimento Econômico (OCDE). No Brasil, o valor anual estimado para o aluno do ensino médio urbano no Distrito Federal na rede pública, em 2008, foi projetado em 843, enquanto o responsável por um filho único teria arcado com 3.755, incluindo o reforço escolar, fora a carga tributária, que sustenta, inclusive, a rede escolar pública. Longe de recair no simplismo de que a educação quanto mais cara é melhor, essas diferenças interpaíses refletem desigualdades de desenvolvimento.

\section{Considerações finais: os rios correm para o mar?}

Apesar do caráter exploratório do estudo, com o qual não se pretende generalizar os resultados, nada impede que algumas conclusões ou inferências sejam tecidas. 
No que tange ao gasto realizado pelas famílias com reforço e educação extraescolar em geral, os resultados confirmam o que ocorre em outros sistemas educacionais, ou seja: numerosas famílias tendem a investir mais na educação dos filhos para assegurar-lhes o sucesso, sobretudo em situações competitivas, como o acesso à educação superior pública no caso do Brasil, gratuita. Essa disposição é compensadora em face da reprovação ou do abandono, que implicaria o custo de oportunidade de um ano perdido, além, no caso da escola particular, de mais uma anuidade.

Por sua vez, a frequência à escola pública, embora gratuita, envolve diversas despesas, chamadas de custos indiretos, como transporte, material, alimentação, além do reforço e da educação extraescolar. Esses valores, em termos relativos, são inversamente proporcionais à renda domiciliar, mostrando-se muito mais onerosos às famílias economicamente menos aquinhoadas.

Uma constatação divergente da literatura concerne à influência do nível de escolaridade da mãe sobre os gastos com reforço escolar: os resultados da pesquisa não apontaram qualquer evidência que corrobore essa tese. No entanto, os dados sugeriram uma possível associação entre a escolaridade da mãe e o interesse do estudante no ensino técnicoprofissional: os filhos de mães com menor escolaridade estariam mais propensos a frequentar essa modalidade. Trata-se de uma constatação coerente com as expectativas históricas das camadas sociais menos favorecidas, a cujos filhos tem sido dada, quando muito, a oportunidade de frequentar a escola pública.

Por fim, no que tange à perspectiva de ingresso na educação superior como uma das grandes motivações para o reforço escolar, os dados da pesquisa apontaram tratar-se de tese plausível, a contemplar, igualmente, estudantes de famílias com menor escolaridade, vinculados à escola pública, e seus pares de famílias mais abastadas, que cursam escola privada.

Essas constatações perdem sentido, pelo menos em parte, se não forem consideradas à luz do que ocorre nas escolas e na educação pública e privada do País. Subjacente a essa busca de reforço escolar, além da competição por vagas na educação superior e no trabalho, existe a menor qualidade da escola pública, patenteada pelas avaliações. Enquanto os mais aquinhoados conseguem, senão suprir, pelo menos remediar a qualidade, os menos favorecidos não contam com a mesma alternativa.

Uma última questão envolve trabalhos de prosseguimento das pesquisas. A eficácia do reforço escolar, representada pela garantia de ingresso na universidade pública, poderia ser aferida em estudo com estudantes dos primeiros anos da educação superior, de onde poderiam surgir evidências conclusivas a esse respeito. Isso é notadamente relevante para permitir aos pais e à sociedade avaliação mais consistente do retorno do investimento em reforço escolar, o que pode levá-los a uma postura de comprometimento com a escola pública em caso de detecção de resultados não favoráveis. Outra questão a investigar é a das deficiências da escola, reveladas pela busca de reforço e educação extraescolar. Embora incômoda, não se criariam empresas transnacionais se a escola desse conta do recado. 
ANDERSON, Leslie M.; LAGUARDA, Katrina G. Case studies of supplemental services under the No Child Left Behind Act: findings from 2003-04. Washington, D.C.: U.S. Department of Education, 2005. Disponível em: <http://www.edgov/rschstat/eval/disadv/ supplementalyear2/final-year2.pdf>. Acesso em: 11 jun. 2007.

BALFANZ, Robert; McPARTLAND, James; SHAW, Alta.

Re-conceptualizing extra help for high school students in a high standards era. Center for Social Organization of Schools, Johns Hopkins University, 2002. Disponível em: < http://www.earlycolleges.org/ Downloads/ReconcepBalfanz.pdf> . Acesso em: 11 jun. 2007.

BOURDIEU, Pierre; PASSERON, Jean-Claude. La reproduction: éléments pour une théorie du système d'enseignement. Paris: Minuit, 1970.

BRASIL. Instituto Nacional de Estudos e Pesquisas Educacionais Anísio Teixeira (Inep). Investimentos públicos em educação: despesas públicas em educação por aluno segundo o nível de ensino, preços nominais - Tabela 2: Estimativa do investimento público direto em educação por estudante, por nível de ensino, valores nominais, Brasil 2000-2008. Disponível em: <http://www.inep.gov.br/estatisticas/ gastoseducacao/despesas_publicas/P.A._precos.htm>. Acesso em: 15 maio 2009.

BRASIL. Ministério da Educação. Fundo Nacional de Desenvolvimento da Educação. Valor anual por aluno estimado, no âmbito do Distrito Federal e dos Estados, e estimativa de receita do Fundo de Manutenção e Desenvolvimento da Educação Básica e de Valorização dos Profissionais da Educação - 2008 (Portaria Interministerial no 1.027, de 19 de Agosto de 2008 - (Anexo 1). Disponível em: ftp://ftp.fnde.gov.br/web/fundeb/ valor_aluno_receita_anual_2008.pdf. Acesso em: 15 maio 2009.

BRASIL. Ministério da Fazenda. Receita Federal. Instruções de preenchimento - modelo completo. Disponível em: http://www.receita. fazenda.gov.br/PessoaFisica/IRPF/2008/Orientacoes/Orienta.htm. Acesso em: 16 maio 2009.

BRAY, Mark. Private supplementary tutoring: comparative perspectives on patterns and implications. In: OXFORD INTERNATIONAL CONFERENCE ON EDUCATION AND DEVELOPMENT 'LEARNING AND LIVELIHOOD', 2005. Disponível em: <www.hku.hk/eroesite/html/ press/oxford.pdf. >. Acesso em: 7 out. 2008. 
BRAY, Mark. As explicações em perspectiva comparada: implicações no trabalho dos professores e no funcionamento das escolas. In: COSTA, Jorge Adelino; NETO-MENDES, António; VENTURA, Alexandre. Xplica: investigação sobre o mercado das explicações. Aveiro: Universidade de Aveiro, 2008, p. 11-26.

COSTA, Jorge Adelino et al. O fenômeno das explicações: aspectos da realidade portuguesa e do contexto global. Ensaio: Avaliação e Políticas Públicas em Educação, Rio de Janeiro, v. 15, n. 57, out./dez. 2007. Disponível em: <http://www.scielo.br/scielo.php?pid=S010440362007000400002\&script $=$ sci_arttext\&tlng $=$ ES $>$. Acesso em: 16 ago. 2008.

COSTA, Jorge Adelino da; NETO-MENDES, António; VENTURA, Alexandre. Xplica: investigação sobre o mercado das explicações. Aveiro: Universidade de Aveiro, 2008.

EDUCATION SUPPORTING PROJECT (ESP). Education in a hidden marketplace: monitoring of private tutoring. Budapest: Education Support Program (ESP) of the Open Society Institute, 2006. Disponível em: <http://www.edupolicy.net/explorer/streamer.php?dwn=166>. Acesso em: 4 nov. 2008.

KIM, Taejong. Shadow education: school quality and demand for private tutoring in Korea. Discussion Paper n. 055, Kyoto University: 21 COE Interfaces for Advanced Economic Analysis. Disponível em: < http:// www.kier.kyoto-u.ac.jp/coe21/dp/51-60/21 COE-DP055.pdf> . Acesso em: 11 mar. 2007.

NETO-MENDES, Antonio et al. La industria de las clases particulares: de la actividad liberal a la franquicia de las multinacionales. Comunicação apresentada no evento Pedagogía 2007: Encuentro por la unidad de los educadores, Havana, 2007.

SHAFIQ, M. Najeeb. The economic burden of private tutoring expenses on households in developing countries: the case of Bangladesh. 2002. Disponível em: < http://www.tc.columbia.edu/students/see/events/ Shafiq\%20-\%202-19-02.pdf>. Acesso em: 30 set. 2008.

TANSEL, Aysit; BIRCAN, Fatma. Private tutoring expenditures in Turkey. 2004. Disponível em < http://www.ftp.iza.org/dp1609.pdf>. Acesso em: 3 out. 2008.

Effect of private tutoring on university entrance examination in Turkey. May 2005. Disponível em < http://www.tek.org. tr/dosyalar/A-Tansel-May-04.pdf>.. Acesso em: 3 out. 2008. 
Candido Gomes, doutor em Educação pela University of California, é professor titular fundador da Universidade Católica de Brasília e coordenador da Cátedra Unesco de Juventude, Educação e Sociedade da mesma Universidade.

clgomes@terra.com.br

Fernando Mariano, mestrando em Educação na Universidade Católica de Brasília, é consultor legislativo do Senado Federal.

fmariano@senado.gov.br

Adriana de Oliveira é mestranda em Educação na Universidade Católica de Brasília.

adriana.oliveira@sesi.org.br

Alessandro Barbosa é mestrando em Educação na Universidade Católica de Brasília.

alessandroximenes@hotmail.com

José Hilton B. de Sousa é mestrando em Educação na Universidade Católica de Brasília.

josehilton11@yahoo.com.br

Nidolf Friedrich é mestrando em Educação na Universidade Católica de Brasília.

nidolffredrich@lasallenb.org.br

Recebido em 14 de agosto de 2009.

Aprovado em 15 de dezembro de 2009. 